\title{
Propuesta preliminar para la estructuración de las relaciones laborales entre los docentes de pedagogía terapéutica y audición y lenguaje.
}

\author{
(Preliminary proposal for the structuring of labor relations among teachers of \\ therapeutic pedagogy and hearing and language.)
}

\author{
Adrián Jesús Ricoy Cano \\ Universidad de Jaén, España.
}

Fecha recepción: 01-03-2018

Páginas 29-43

Fecha aceptación: 30-06-2018

\section{Resumen.}

En el presente artículo se muestra una propuesta de relación y coordinación laboral formal entre los docentes de pedagogía terapéutica y de audición y lenguaje. El objetivo que se pretende es generar una base sólida, basada en investigaciones similares anteriores, que pueda usarse si en algún momento las políticas educativas proponen legislar sobre este ámbito. A lo largo de esta revisión, se expondrán estudios que guardan relación con esta temática, aunque a día de hoy no hay ninguna investigación concreta sobre esta propuesta. La estructura que se ha seguido para la creación de este artículo ha sido la siguiente: primero se ha introducido el tema, posteriormente se ha caracterizado al maestro de pedagogía y audición y lenguaje, a continuación, se ha desarrollado un recorrido legislativo con relación al tópico, se han mostrado los antecedentes, se han explicado las funciones de ambos docentes y por último se ha desarrollado la iniciativa.

Palabas clave: propuesta; docente; pedagogía terapéutica; audición y lenguaje; legislación

\section{Abstract.}

The following paper is shown a proposal for closer relations and coordination in the working environment among teachers of therapeutic pedagogy and hearing and speech. The objective is to reach a solid base, based on previous similar researchs, that can be used if at any time educational policies propose legislation on this área. Throughout this review will be presented studies related to this subject, although today there is no concrete research on this proposal. The structure that has been followed for the creation of this article has been the following: first the subject has been introduced, later the teacher of pedagogy and hearing and language has been characterized, then a legislative course has been developed in relation to the topic, the background has been shown, the functions of both teachers have been explained and finally the initiative has been developed.

Keywords: proposal; teacher; therapeutic pedagogy; hearing and speech; legislation 


\section{1.-Introducción.}

El concepto de educación especial ha sufrido a lo largo de la historia innumerables modificaciones. Tales reestructuraciones afectaron, como es lógico, a la situación de las personas con necesidades específicas de apoyo educativo. En la actualidad, como propuesta más reciente en atención a la diversidad se está tratando de pasar desde las concepciones de la educación especial a las de la educación inclusiva.

Es cierto que la situación tanto dentro de la sociedad como más específicamente en el ámbito escolar de las personas con diversidad funcional ha ido mejorando lenta e inexorablemente. Hernández y De Barros (2016), señalan que desde considerar que estas personas no merecían vivir y ser arrojados por el monte Taijeto en Esparta 0 por la roca Tarpeia en Roma, hasta hablar de personas con necesidades específicas de apoyo educativo ha pasado un buen periodo de tiempo. La sociedad en la que vivimos ha sufrido importantes modificaciones y progresos en la mayoría de los ámbitos y la atención a la diversidad desde los centros docentes se ha ido adaptando en paralelo a dichos cambios.

En esta revisión se plasmará el recorrido legislativo que se ha seguido a lo largo de la historia para atender al alumnado con necesidades específicas de apoyo educativo. Más específicamente en este artículo se mostrarán cuáles son las funciones de los docentes de pedagogía terapéutica y audición y lenguaje. Una vez definidas, se llevará a cabo una propuesta donde se tratará de estructurar de manera formal unas pautas para la relación entre los docentes de pedagogía terapéutica y audición y lenguaje. Todo ello siguiendo las directrices de la legislación vigente e investigaciones previas. Es un hecho que en la actualidad los maestros y maestras de pedagogía terapéutica y audición y lenguaje mantienen un contacto habitual y una coordinación real, ambos aspectos no regulados, derivado de la necesidad de dar una atención completa y de calidad al alumnado que tienen en común. Por eso, el propósito de este estudio es presentar una base sólida sobre la que poder legislar al respecto y que en un futuro sirva de guía a los docentes de ambas especialidades.

\section{2.-Definición de maestrola de pedagogía terapéutica y audición y lenguaje.}

Son muchas las respuestas que se dan desde la educación a la atención a la diversidad tales como: recursos (extraordinarios y ordinarios), medidas de flexibilización curricular, organización escolar, orientación y acción tutorial. (Hernández y De Barros, 2016)

Como forma de atender al alumnado con diversidad, se ha creado el Equipo de Apoyo a la Diversidad. Este Equipo se compone en la actualidad por los siguientes perfiles profesionales:

- Maestro/a especialista en Audición y Lenguaje, Maestro/a especialista en Pedagogía Terapéutica, Maestro/a especialista en lenguaje de signos Maestro/a de Apoyo, un miembro del E.O.E. 
Dentro de esta respuesta, en este artículo se va a destacar las figuras de los docentes de pedagogía terapéutica y audición y lenguaje. Resulta difícil dar una definición acertada sobre estos docentes. Salas, M.R (2016), dice que debemos de pensar en la importancia de los PT en la escuela actual, en la que, si realmente creemos en lo que se proclama como filosofía educativa predominante, la integración y la inclusión, se convierten en colaboradores necesarios para los profesores de aula y tutores. En este sentido, los PT deben ser maestros cuya formación complementaria abarque una serie de conocimientos y estrategias que le permitan colaborar con los docentes en las distintas etapas educativas para facilitar el logro de objetivos educativos de todos y cada uno de los alumnos de un aula. Los maestros PT son, en este contexto, un inestimable recurso humano al servicio de alumnos, profesores, tutores, equipo directivo y familias.

Por otro lado, se encuentran los docentes de audición y lenguaje. De acuerdo con la definición aportada por la Federación de Enseñanza de CC.OO. de Andalucía (2009), el maestro/a de audición y lenguaje es el profesional que suele confundirse con el logopeda, ya que realiza trabajos similares de prevención, diagnóstico, pronóstico, tratamiento y evaluación de los trastornos de la comunicación humana. La característica diferencial entre ambos es que mientras el Logopeda, como profesional sanitario podemos encontrarlo, en marco clínico, el maestro de audición y lenguaje trabaja fundamentalmente en contextos educativos.

Sintetizando, entre los recursos humanos disponibles para la atención a la diversidad en los centros educativos, se encuentran los profesionales que componen el Equipo de Apoyo a la Diversidad. Dentro de este equipo se encontrarían los maestros de pedagogía terapéutica y audición y lenguaje. Cada uno de estos especialistas tienen unas funciones claras y bien definidas en las legislaciones correspondientes. Sin embargo, el vacío legal o falta de ordenación se encontraría en la estructuración de una relación laboral entre dichos docentes. Por este motivo, en los siguientes apartados se tratará de exponer unos fundamentos básicos que podrían servir de base en un futuro.

\section{3.-Historia legislativa.}

Como se anticipó las funciones en el entorno de trabajo de los profesionales especialistas de audición y lenguaje y de pedagogía terapéutica vienen marcadas en las diferentes legislaciones educativas referentes. En este epígrafe se hará un recorrido legislativo, marcando cómo ha ido evolucionando la atención a la diversidad a lo largo de la historia. Aparecerán especificaciones de cómo se ha de atender a la diversidad de acuerdo a las leyes educativas promulgadas por el Estado Español.

3.1.-Ley 14/1970, de 4 de agosto, General de Educación y Financiamiento de la Reforma Educativa.

Se comenzará con la Ley 14/1970, de 4 de agosto, General de Educación y Financiamiento de la Reforma Educativa. En dicha ley se recogen, en el Título I, 
Capítulo VII, art. 49 al 53, aspectos relacionados con la Educación Especial. Cerdá, M. e lyanga, A. (2013), lo agrupan de la siguiente manera:

Art. 49.1, "Tendrá como finalidad preparar, mediante el tratamiento educativo adecuado, a todos los deficientes e inadaptados para una incorporación a la vida social tan plena como sea posible en cada caso, según sus condiciones y resultado del Sistema Educativo; y a un sistema de trabajo en todos los casos posibles, que les permita servirse a sí mismos y sentirse útiles a la sociedad".

Art. 50, medios y diagnóstico.

Art.51, escolarización en centros especiales o en unidades especiales de centros ordinarios.

Art. 52, objetivos, estructuras, duración, programas y límites de la Educación de la Educación Especial.

\section{2.-Ley Orgánica 8/1985, de 3 de julio, reguladora del Derecho a la Educación.}

En su Título preliminar dice:

-Artículo primero: Todos los españoles tienen derecho a una educación básica que les permita el desarrollo de su propia personalidad y la realización de una actividad útil a la sociedad. Esta educación será obligatoria y gratuita en el nivel de educación general básica y, en su caso, en la formación profesional de primer grado, así como en los demás niveles que la ley establezca.

-Artículo sexto: 1. Todos los alumnos tienen los mismos derechos y deberes, sin más distinciones que las derivadas de su edad y del nivel que estén cursando. 3. Se reconocen a los alumnos los siguientes derechos básicos: $h$ ) A recibir las ayudas y los apoyos precisos para compensar las carencias y desventajas de tipo personal, familiar, económico, social y cultural, especialmente en el caso de presentar necesidades educativas especiales, que impidan o dificulten el acceso y la permanencia en el sistema educativo.

3.3.-Ley Orgánica 1/1990, de 3 de octubre, de Ordenación General del Sistema Educativo.

En su capítulo V De la educación especial dice así:

-Artículo 36: 1. El sistema educativo dispondrá de los recursos necesarios para que los alumnos con necesidades educativas especiales, temporales o permanentes, puedan alcanzar dentro del mismo sistema los objetivos establecidos con carácter general para todos los alumnos. 2. La identificación y valoración de las necesidades educativas especiales se realizará por equipos integrados por profesionales de distintas cualificaciones. que establecerán en cada caso planes de actuación en 
relación con las necesidades educativas específicas de los alumnos. 3. La atención al alumnado con necesidades educativas especiales se regirá por los principios de normalización y de integración escolar. 4. Al final de cada curso se evaluarán los resultados conseguidos por cada uno de los alumnos con necesidades educativas especiales en función de los objetivos propuestos a partir de la valoración inicial. Dicha evaluación permitirá variar el plan de actuación en función de sus resultados.

Artículo 37: 1. Para alcanzar los fines señalados en el artículo anterior, el sistema educativo deberá disponer de profesores de las especialidades correspondientes y de profesionales cualificados, así como de los medios y materiales didácticos precisos para la participación de los alumnos en el proceso de aprendizaje. Los centros deberán contar con la debida organización escolar y realizar las adaptaciones y diversificaciones curriculares necesarias para facilitar a los alumnos la consecución de los fines indicados. Se adecuarán las condiciones físicas y materiales de los centros a las necesidades de estos alumnos. 2. La atención a los alumnos con necesidades educativas especiales se iniciará desde el momento de su detección. A tal fin, existirán los servicios educativos precisos para estimular y favorecer el mejor desarrollo de estos alumnos y las Administraciones educativas competentes garantizarán su escolarización. 3. La escolarización. en unidades 0 centros de educación especial solo se llevará a cabo cuando las necesidades del alumno no puedan ser atendidas por un centro ordinario. Dicha situación será revisada periódicamente, de modo que pueda favorecerse, siempre que sea posible, el acceso de los alumnos a un régimen de mayor integración. 4. Las Administraciones educativas regularán y favorecerán la participación de los padres 0 tutores en las decisiones que afecten a la escolarización de los alumnos con necesidades educativas especiales.

\section{4.-Ley Orgánica 10/2002, de 23 de diciembre, de Calidad de la Educación.}

En su Capítulo VII De la atención a los alumnos con necesidades educativas específicas, Sección $1 .^{\text {a }}$ de la igualdad de oportunidades para una educación de calidad dice así:

Artículo 40. Principios: 1. Con el fin de asegurar el derecho individual a una educación de calidad, los poderes públicos desarrollarán las acciones necesarias y aportarán los recursos y los apoyos precisos que permitan compensar los efectos de situaciones de desventaja social para el logro de los objetivos de educación y de formación previstos para cada uno de los del sistema educativo.

Artículo 45. Valoración de necesidades: 1. Los alumnos con necesidades educativas especiales serán escolarizados en función de sus características, integrándolos en grupos ordinarios, en aulas especializadas en centros ordinarios, en centros de educación especial o en escolarización combinada. 2. La identificación y valoración de las necesidades educativas especiales de estos alumnos se realizará por equipos integrados por profesionales de distintas cualificaciones. Estos profesionales establecerán en cada caso planes de actuación en relación con las necesidades 
educativas de cada alumno, contando con el parecer de los padres y con el del equipo directivo y el de los profesores del centro correspondiente. 3. Al finalizar cada curso, el equipo de evaluación valorará el grado de consecución de los objetivos establecidos al comienzo del mismo para los alumnos con necesidades educativas especiales. Los resultados de dicha evaluación permitirán introducir las adaptaciones precisas en el plan de actuación, incluida la modalidad de escolarización.

Artículo 46. Escolarización: 1. La escolarización de los alumnos con necesidades educativas especiales comenzará y finalizará con las edades establecidas con carácter general para el nivel y la etapa correspondiente. Excepcionalmente, podrá autorizarse la flexibilización del periodo de escolarización en la enseñanza obligatoria. En cualquier caso, el límite de edad para poder permanecer escolarizado en un centro de educación especial será de veintiún años. 2. La escolarización de alumnos con necesidades educativas especiales incluirá también la orientación a los padres para la necesaria cooperación entre la escuela y la familia.

Artículo 47. Recursos de los centros: 1. Las Administraciones educativas dotarán a los centros sostenidos con fondos públicos del personal especializado y de los recursos necesarios para garantizar la escolarización de alumnos con necesidades educativas especiales. En la programación de la oferta de puestos escolares gratuitos, se determinarán aquellos centros que, por su ubicación y sus recursos, se consideren los más indicados para atender las diversas necesidades de estos alumnos.

\section{5.-Ley Orgánica 2/2006, de 3 de mayo, de Educación.}

Son tales las repercusiones en atención a la diversidad en esta ley, que se abreviará a los puntos más destacados:

Dicha ley en su Título II Equidad en la Educación, más específicamente en su Capítulo Alumnado con necesidad específica de apoyo educativo, menciona diferentes artículos como:

Artículo 71. Principios. En este artículo se plasman los principios básicos para la atención a la diversidad.

Artículo 72. Recursos: En este apartado se muestran los recursos destinados para la atención a la diversidad.

De aquí en adelante se comienzan a citar artículos relacionados, con la definición, la escolarización, programas específicos, medidas de escolarización y atención de cada uno de los grupos que forman el alumnado con necesidades específicas de apoyo educativo (engloba al alumnado con necesidades educativas especiales, al alumnado con altas capacidades intelectuales, al alumnado con dificultades específicas de aprendizaje y al alumnado que precisa actuaciones de carácter compensatorio.) 
3.6.-Ley Orgánica 8/2013, de 9 de diciembre, para la mejora de la calidad educativa.

La Ley Orgánica 8/2013, de 9 de diciembre, de Mejora de la Calidad Educativa es la última ley orgánica introducida por el gobierno español, en ella se hacen diferentes modificaciones y reestructuraciones a la Ley Orgánica 2/2006 de 3 de mayo de Educación. Una de estas modificaciones afecta al Título II "Equidad en la Educación". Incluyendo dentro de este grupo a los trastornos por déficit de atención e hiperactividad y a los alumnos de Incorporación tardía al Sistema Educativo.

Además de todas las leyes educativas aquí mencionas, existen una gran cantidad de Reales Decretos, Decretos, Órdenes e instrucciones que regulan la atención a la diversidad entre ellos desde esta revisión se destacan:

- Decreto 696/95 de 28 de abril, sobre ordenación de la Educación Especial: en su artículo 8 menciona como recursos, a los profesores especialistas en pedagogía terapéutica y en audición y lenguaje, Decreto 1344/91 de 6 de septiembre, sobre el Currículo de Educación Primaria: en su artículo 9 señala que los profesores tutores se coordinarán con los profesores de apoyo, Real Decreto 82/1996 de 26 de enero, por el que se aprueba el Reglamento Orgánico de las Escuelas de Educación Infantil y de los Colegios de Educación Primaria: En su artículo 24. g), se dice: Es competencia del claustro coordinar las funciones referentes a la orientación, tutoría, evaluación y recuperación de los alumnos; en su artículo 34. g) Criterios y procedimientos para realizar las ACIS de los ACNEE.

\section{4.-Antecedentes.}

No son muchas las referencias previas sobre las relaciones entre los docentes de pedagogía terapéutica y audición y lenguaje, sin embargo, si hay estudios que evidencian esta falta de coordinación profesional y muestran unos resultados llamativos que sirven como referencia para la creación de esta propuesta. A continuación, se hablará sobre los estudios analizados que guardan relación con esta temática y que han servido como apoyo para esta revisión.

Tabla 1. Investigaciones previas.

\begin{tabular}{|c|c|c|}
\hline Investigación & Desarrollo & Resultados \\
\hline $\begin{array}{l}\text { Luque, A. y } \\
\text { Carrión, J.J. (2013). } \\
\text { Análisis del grado } \\
\text { de satisfacción } \\
\text { profesional del } \\
\text { maestro r de } \\
\text { audición } \\
\text { y } \\
\text { itinerante. }\end{array}$ & $\begin{array}{l}\text { En esta investigación se } \\
\text { presenta una metodología } \\
\text { cualitativa para la toma de } \\
\text { información. } \\
\text { La población seleccionada } \\
\text { para el estudio serían } \\
\text { maestros de audición y } \\
\text { lenguaje itinerantes de } \\
\text { Almería. }\end{array}$ & $\begin{array}{l}\text { En cuanto a los resultados } \\
\text { relacionados con la } \\
\text { frustración profesional de } \\
\text { estos docentes y sus quejas } \\
\text { por la falta de una } \\
\text { relación/coordinación laboral } \\
\text { satisfactoria encontramos: } \\
\text {-El sentimiento de frustración } \\
\text { ante la manera de llevar a }\end{array}$ \\
\hline
\end{tabular}




\begin{tabular}{|c|c|c|}
\hline & $\begin{array}{l}\text { El objeto-problema de este } \\
\text { estudio consiste en realizar } \\
\text { un análisis de la } \\
\text { situación que viven los } \\
\text { profesionales itinerantes de } \\
\text { audición y lenguaje, } \\
\text { profundizando en el estudio } \\
\text { del grado de satisfacción } \\
\text { profesional acerca de la } \\
\text { actuación que vienen } \\
\text { desarrollando. }\end{array}$ & $\begin{array}{l}\text { cabo una labor que } \\
\text { abarcaría muchas más } \\
\text { facetas y cuyos resultados } \\
\text { son escasos y segmentados. } \\
\text {-La ausencia de tiempo para } \\
\text { realizar actuaciones } \\
\text { necesarias de } \\
\text { coordinación, para atender } \\
\text { en tiempo/forma a los } \\
\text { alumnos asignados. }\end{array}$ \\
\hline $\begin{array}{l}\text { Navarro, M.J. } \\
\text { (2008). La dirección } \\
\text { escolar ante el reto } \\
\text { de la diversidad. }\end{array}$ & $\begin{array}{l}\text { "Esta investigación se centra } \\
\text { en el estudio de la función } \\
\text { directiva ante la Atención a la } \\
\text { Diversidad en diferentes } \\
\text { centros educativos". } \\
\text { El desarrollo de este estudio } \\
\text { se basa en el análisis de la } \\
\text { dirección escolar ante el } \\
\text { tratamiento a la diversidad. } \\
\text { Se analizan desde aquí las } \\
\text { necesidades, dualidades e } \\
\text { incertidumbres ante el reto } \\
\text { que supone a los centros } \\
\text { educativos la atención a la } \\
\text { diversidad. } \\
\text { El objetivo principal de la } \\
\text { investigación es conocer los } \\
\text { planteamientos y las } \\
\text { necesidades de los Equipos } \\
\text { Directivos para atender a la } \\
\text { diversidad. } \\
\text { La metodología utilizada es } \\
\text { básicamente descriptiva. } \\
\text { El instrumento utilizado } \\
\text { formado por un cuestionario } \\
\text { de preguntas abiertas. } \\
\text { "La muestra la forman } \\
\text { miembros de Equipos } \\
\text { Directivos de Centros }\end{array}$ & $\begin{array}{l}\text { En cuanto a los resultados } \\
\text { obtenidos en Atención a la } \\
\text { Diversidad se abstrae que es } \\
\text { necesaria una atención } \\
\text { individualizada y } \\
\text { personalizada. } \\
\text { Las cuestiones relacionadas } \\
\text { con la diversidad es un } \\
\text { motivo de preocupación para } \\
\text { los profesionales implicados } \\
\text { en el gobierno de los centros. } \\
\text { Desde este estudio se incita } \\
\text { a crear un cuerpo especial } \\
\text { de gestores-directores, para } \\
\text { atender a la diversidad, ya } \\
\text { que las tareas directivas } \\
\text { requieren una dedicación y } \\
\text { un tiempo del que no } \\
\text { siempre se dispone, } \\
\text { afirmándose que la atención } \\
\text { a la diversidad merecería un } \\
\text { análisis periódico y riguroso, } \\
\text { que no siempre se puede } \\
\text { realizar. } \\
\text { Desde este estudio se } \\
\text { plantea que la solución } \\
\text { a las dificultades sigue } \\
\text { realizándose desde medidas } \\
\text { técnicas perspectiva } \\
\text { individual) slantean } \\
\text { apenas se las que se } \\
\text { soluciones en }\end{array}$ \\
\hline
\end{tabular}




\begin{tabular}{|c|c|c|}
\hline & $\begin{array}{l}\text { Públicos } \\
\text { de Educación Infantil y } \\
\text { Primaria (CPEIP), Centros } \\
\text { Concertados de Educación } \\
\text { Especial (CCEE) y Centros } \\
\text { Concertados de Educación } \\
\text { Infantil y Primaria (CCEIP) de } \\
\text { las provincias de Badajoz y } \\
\text { Sevilla". }\end{array}$ & 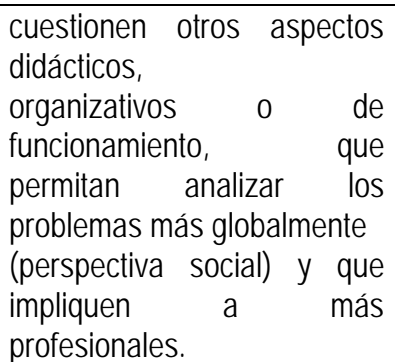 \\
\hline $\begin{array}{l}\text { González, F. y } \\
\text { Méndez, J.A. } \\
\text { (2009). El profesor } \\
\text { de apoyo en los } \\
\text { centros ordinarios: } \\
\text { aspectos didácticos } \\
\text { y funcionales para } \\
\text { la atención a la } \\
\text { diversidad. }\end{array}$ & $\begin{array}{l}\text { "Desde este estudio se } \\
\text { muestran las funciones tanto } \\
\text { didácticas como } \\
\text { organizativas, de los } \\
\text { docentes de Pedagogía } \\
\text { Terapéutica y Audición y } \\
\text { Lenguaje que garantiza una } \\
\text { respuesta adecuada a las } \\
\text { necesidades de todo } \\
\text { alumnado". } \\
\text { Para el desarrollo de esta } \\
\text { investigación se utilizó un } \\
\text { cuestionario de escala Likert. } \\
\text { Se trata de una investigación } \\
\text { de tipo cuantitativa con un } \\
\text { diseño de tipo descriptivo- } \\
\text { explorativo. La muestra está } \\
\text { constituida por } 60 \text { profesores } \\
\text { de pedagogía terapéutica y } \\
\text { audición y lenguaje. }\end{array}$ & $\begin{array}{l}\text { En cuanto a los resultados } \\
\text { obtenidos. En relación a los } \\
\text { recursos y servicios con los } \\
\text { que cuentan los centros, se } \\
\text { pone énfasis en la necesidad } \\
\text { de más recursos humanos, } \\
\text { mientras los espacios y } \\
\text { materiales son suficientes. } \\
\text { En cuanto a las propuestas } \\
\text { de mejora planteadas en } \\
\text { este estudio se destaca una } \\
\text { que guarda relación con } \\
\text { nuestro artículo: } \\
\text {-En relación al profesorado } \\
\text { indican que es necesario } \\
\text { ofrecer más formación para } \\
\text { la actuación directa con el } \\
\text { alumnado con necesidades } \\
\text { específicas de apoyo } \\
\text { educativo y motivar e } \\
\text { incentivar la coordinación } \\
\text { educativa entre los } \\
\text { profesores. }\end{array}$ \\
\hline
\end{tabular}

Fuente: elaboración propia

\section{5.- Funciones del profesorado especialista en pedagogía terapéutica.}

Antes de mostrar la propuesta de relación entre los docentes especialistas de pedagogía terapéutica y audición y lenguaje se verán las funciones que desempeñan ambos profesionales, siguiendo siempre las pautas legislativas que organizan dicho funcionamiento.

De acuerdo con la ORDEN de 20 de agosto de 2010, por la que se regula la organización y el funcionamiento de las escuelas infantiles de segundo ciclo, de los 
colegios de educación primaria, de los colegios de educación infantil y primaria y de los centros públicos específicos de educación especial, así como el horario de los centros, del alumnado y del profesorado. En su Artículo 19. Profesorado especializado para la atención del alumnado con necesidades educativas especiales. 1. Sin perjuicio de lo recogido en el artículo 7 del Reglamento Orgánico de las escuelas infantiles de segundo ciclo, de los colegios de educación primaria, de los colegios de educación infantil y primaria y de los centros públicos específicos de educación especial, el maestro o maestra especializado para la atención del alumnado con necesidades educativas especiales tendrá, al menos, las siguientes funciones específicas:

a) La atención e impartición de docencia directa para el desarrollo del currículo al alumnado con necesidades educativas especiales cuyo dictamen de escolarización recomiende esta intervención. Asimismo, podrá atender al alumnado con otras necesidades específicas de apoyo educativo en el desarrollo de intervenciones especializadas que contribuyan a la mejora de sus capacidades.

b) La realización, en colaboración con el profesorado del área encargado de impartirla y con el asesoramiento del equipo de orientación, de las adaptaciones curriculares significativas, de conformidad con lo establecido en el artículo 15 de la Orden de 25 de julio de 2008.

c) La elaboración y adaptación de material didáctico para la atención educativa especializada del alumnado con necesidades educativas especiales, así como la orientación al resto del profesorado para la adaptación de los materiales curriculares.

d) La tutoría del alumnado con necesidades educativas especiales al que imparte docencia, en los términos previstos en el apartado 3.

e) La coordinación con los profesionales de la orientación educativa, con el personal de atención educativa complementaria y con otros profesionales que participen en el proceso educativo del alumnado con necesidades educativas especiales.

3. De conformidad con lo recogido en el artículo 89.1 del Reglamento Orgánico de estos centros, la tutoría del alumnado con necesidades educativas especiales será ejercida en las aulas específicas de educación especial por el profesorado especializado para la atención de este alumnado. En el caso del alumnado con necesidades educativas especiales escolarizados en un grupo ordinario, la tutoría será ejercida de manera compartida entre el maestro o maestra que ostente la tutoría del grupo donde está integrado y el profesorado especialista. A tales efectos, el plan de orientación y acción tutorial recogerá los mecanismos de coordinación entre ambos docentes y las actuaciones a realizar por cada uno de ellos 0 de forma conjunta. En todo caso, la atención a las familias de este alumnado se realizará conjuntamente, lo que será previsto en el horario individual de este profesorado. 
Desde esta revisión se destaca el apartado (e), mencionado anteriormente y el cual hace referencia a la coordinación laboral entre docentes del sistema educativo para una mejora en atención a la diversidad. Sin embargo, se puede apreciar cómo a pesar de hablar de la necesidad de mantener una coordinación profesional, no especifica cómo se llevaría a cabo, ni tampoco muestra la estructuración que seguiría. Será pues objeto del presente artículo plantear dichas pautas relacionales.

\section{6.-Funciones del profesorado especialista en audición y lenguaje.}

Con respecto a las funciones del profesorado especialista en audición y lenguaje se seguirá la esquematización aportada por la Federación de Enseñanza de la Conferencia Sindical de Comisiones Obreras (2009), la cual especifica las funciones de estos especialistas y las resume de la siguiente manera; el Maestro/a de Audición y Lenguaje es el profesional encargado de:

- Realizar intervenciones directas de apoyo a aquellos alumnos que presenten especiales dificultades, manteniendo una estrecha relación de coordinación con el resto del profesorado encargado de la educación del menor, y en especial, con el tutor correspondiente.

- Participar en la elaboración y asesoramiento de la parte del currículo escolar que se refiera a aspectos lingüísticos, así como, en aquellas programaciones de ciclo o de aula y adaptaciones curriculares.

- Asesorar al profesorado en la programación de actividades para la prevención y el tratamiento de dificultades en las áreas de comunicación y lenguaje. Importantísimo es fomentar en sus compañeros la realización de dichas actuaciones, informándoles de la relevancia de las mismas, así como de lo imprescindible que es colaboración del resto del profesorado en la labor del Maestro/a de Audición y Lenguaje.

- Evaluar y valorar la necesidad, o no, de atención educativa especial para aquellos alumnos que presenten déficits relacionadas con la comunicación y el lenguaje.

- Proporcionar información, orientación, material y colaboración a los tutores y profesores de apoyo. También participará con los mismos en la realización de aquellas adaptaciones curriculares precisas cuando el área a transformar o retocar sea la referente a lenguaje y comunicación.

- El contacto con sus compañeros ha de ser continuo, para lo cual debe de mantener reuniones periódicas para la evaluación y seguimiento de sus alumnos, así como para informar y dar pautas de intervención a los profesores y familiares. 
Se puede apreciar como en el caso de los docentes especialistas en Audición y Lenguaje se promueve nuevamente un contacto periódico con el resto de profesionales y especialistas. Pero tampoco se específica cómo se llevaría a cabo, aunque, en este caso sí se presenta de manera genérica en qué se basaría dicha relación/coordinación.

\section{7.-Propuesta para el establecimiento de unas pautas relacionales laborales entre los docentes de pedagogía terapéutica y audición y lenguaje.}

En este epígrafe se presenta una propuesta mediante la cual se pretende mejorar la forma en que los profesionales de los centros educativos se organizan y coordinan con la finalidad de mejorar la atención a la diversidad desde las bases del sistema educativo. De manera general este estudio va destinados a los miembros que componen el Equipo de Orientación (EO).

De una forma más específica esta propuesta se centra en los docentes de pedagogía terapéutica y audición y lenguaje.

Se ha podido valorar a lo largo de esta revisión como la legislación educativa vigente tanto a nivel nacional como autonómico engloba la coordinación entre los diferentes profesionales encargados de la atención del alumnado con diversidad. A pesar de esto, no explica cómo se ha de ser dicha organización/gestión. A continuación, se señalará de manera esquematizada la propuesta realizada tras haber realizado este estudio.

Bajo las directrices de esta nueva organización aparecería una nueva figura, la cual ya fue propuesta con anterioridad por Navarro, M.J. (2008). Esta autora propuso en el año 2008 crear un cuerpo especial de gestores-directores, para atender a la diversidad. Desde este estudio y siguiendo los pasos de Navarro, M.J (2008), se plantea crear una nueva figura conocida como Gestor del Equipo de Orientación (GEO).

La organización que se mantendría, sobre todo horaria, entre el Gestor del Equipo de Orientación, los docentes especialistas de pedagogía terapéutica y audición y lenguaje, así como con las familias sería la que aparece en la siguiente tabla.

Tabla 2. Propuesta preliminar para la estructuración de las relaciones laborales entre los docentes de pedagogía terapéutica y audición y lenguaje.

\begin{tabular}{|l|l|l|lr|}
\hline & $\begin{array}{l}\text { Gestor del Equipo } \\
\text { de Orientación }\end{array}$ & $\begin{array}{l}\text { Maestro/a de } \\
\text { pedagogía } \\
\text { terapéutica }\end{array}$ & $\begin{array}{l}\text { Maestrola de } \\
\text { audición } \\
\text { lenguaje }\end{array}$ & $\begin{array}{r}|c| \\
\text { y }\end{array}$ \\
\hline $\begin{array}{l}\text { Organización } \\
\text { temporal }\end{array}$ & $\begin{array}{l}\text { Una vez a la semana, al inicio de la misma (todos los lunes por la } \\
\text { mañana), se reunirían estos tres profesionales. }\end{array}$ \\
\hline Estructura & Con el objetivo de ir programando, desarrollando y evaluando de \\
\hline
\end{tabular}




\begin{tabular}{|l|l|}
\hline relacional & $\begin{array}{l}\text { manera continua el desarrollo del alumnado con diversidad, y de } \\
\text { esta manera acabar con los problemas de coordinación }\end{array}$ \\
existentes que se han podido valorar de acuerdo con \\
investigaciones previas, así como con las continuas quejas de los \\
docentes especialistas en cuanto a la dificultad en coordinación y \\
comunicación en el trabajo.
\end{tabular}

\begin{tabular}{|l|l|l|l|}
\hline & \multicolumn{1}{|l|}{$\begin{array}{l}\text { Maestrola de } \\
\text { pedagogía } \\
\text { terapéutica }\end{array}$} & $\begin{array}{l}\text { Maestrola de } \\
\text { audición } \\
\text { lenguaje }\end{array}$ \\
\hline $\begin{array}{l}\text { Organización } \\
\text { temporal }\end{array}$ & $\begin{array}{l}\text { Una vez a la semana, al final de la misma (todos los viernes por } \\
\text { la mañana), se reunirían estos dos especialistas. }\end{array}$ \\
\hline $\begin{array}{l}\text { Estructura } \\
\text { relacional }\end{array}$ & $\begin{array}{l}\text { Con el propósito de valorar la consecución de los objetivos } \\
\text { planteados a corto plazo, así como lograr una mayor efectividad } \\
\text { en cuanto coordinación y comunicación. }\end{array}$ \\
& $\begin{array}{l}\text { Recoger información relevante para presentar al siguiente lunes } \\
\text { cuando se reúnan de nuevo con el Gestor de Equipo de } \\
\text { Orientación. }\end{array}$ \\
\hline
\end{tabular}

\begin{tabular}{|l|l|l|l|}
\hline & $\begin{array}{l}\text { Gestor del Equipo } \\
\text { de Orientación }\end{array}$ & $\begin{array}{l}\text { Maestrola de } \\
\text { pedagogía } \\
\text { terapéutica }\end{array}$ & $\begin{array}{l}\text { Maestro/a de } \\
\text { audición } \\
\text { lenguaje }\end{array}$ \\
\hline $\begin{array}{l}\text { Organización } \\
\text { temporal }\end{array}$ & \multicolumn{3}{|l|}{ Una vez al inicio del trimestre y otra al final del mismo. } \\
\hline $\begin{array}{l}\text { Estructura } \\
\text { relacional }\end{array}$ & $\begin{array}{l}\text { Al inicio para plantear las directrices de cara a todo cuatrimestre. } \\
\text { Al final para apreciar los resultados obtenidos y en base a ellos } \\
\text { realizar las modificaciones que se estimen oportunas. }\end{array}$ \\
\hline
\end{tabular}

\begin{tabular}{|c|c|c|c|c|}
\hline & $\begin{array}{l}\text { Gestor del Equipo } \\
\text { de Orientación }\end{array}$ & $\begin{array}{l}\text { Maestrola de } \\
\text { pedagogía } \\
\text { terapéutica }\end{array}$ & $\begin{array}{l}\text { Maestro/a de } \\
\text { audición y } \\
\text { lenguaje }\end{array}$ & Familias \\
\hline $\begin{array}{l}\text { Organización } \\
\text { temporal }\end{array}$ & \multicolumn{4}{|c|}{ Una vez al inicio del trimestre y otra al final del mismo. } \\
\hline $\begin{array}{l}\text { Estructura } \\
\text { relacional }\end{array}$ & \multicolumn{4}{|c|}{$\begin{array}{l}\text { La coordinación y comunicación no debe realizarse solo entre los } \\
\text { profesionales relacionados con la educación del alumnado con } \\
\text { diversidad, sino, que además la relación con las familias es una } \\
\text { pieza clave que se debe tener en cuenta. }\end{array}$} \\
\hline
\end{tabular}

Fuente: elaboración propia 
Para concluir con este apartado se debe decir, que esta propuesta organizativa no es antagónica con las estructuras organizativas que actualmente se llevan a cabo en los centros docentes. Por el contrario, lo que se pretende con este estudio es aportar unas pautas para especificar más sobre la coordinación docente en los centros. Pues se cree que la legislación vigente no específica lo suficiente al respecto.

\section{8.-Conclusión.}

Investigaciones previas muestran como los docentes especialistas de los centros docentes requieren de unas nociones más detalladas en cuanto a coordinación y comunicación en el entorno laboral. Esto es totalmente comprensible, pues si nos adentramos en la legislación al respecto, las pautas que aparecen sobre estos ámbitos son muy genéricas y faltas de una mayor especificación y desarrollo. Por medio de esta revisión se ha tratado de valorar la situación actual sobre esta temática apoyándonos en investigaciones previas, y facilitar una propuesta con el objetivo de desarrollar lo que levemente aparece en las leyes educativas españolas sobre relación/coordinación entre docentes especialistas.

\section{9.-Bibliografía.}

Conferencia Sindical de Comisiones Obreras (2009). Las Funciones del Maestro/a de Audición y Lenguaje. Temas para la Educación. 1-5. ISSN: 1989-4023

González, F. y Méndez, J.A. (2009). El profesor de apoyo en los centros ordinarios: aspectos didácticos y funcionales para la atención a la diversidad. Actas do X Congresso Internacional Galego-Português de Psicopedagogia, 4246-4255. ISBN- 978-972-8746-71-1

Hernández Fernández, A. y De Barros Camargo, C. (2016). Neurociencia y Tecnología en la Inclusión Educativa. Granada, España: Gami.

Ley 14/1970, de 4 de agosto, General de Educación y Financiamiento de la Reforma Educativa. 6 de agosto de 1970, num 187, pp. 12525 a 12546.

Ley Orgánica 8/1985, de 3 de julio, reguladora del Derecho a la Educación. 4 de julio de 1985, num 159, pp 4 a 21.

Ley Orgánica 1/1990, de 3 de octubre, de Ordenación General del Sistema Educativo. 4 de octubre de 1990, num 238, pp 28927 a 28942.

Ley Orgánica 10/2002, de 23 de diciembre, de Calidad de la Educación. 24 de diciembre de 2002, num 307, pp 45188 a 45220.

Ley Orgánica 2/2006, de 3 de mayo, de Educación. 24 de mayo de 2006, num 106, pp 4 a 105. 
Ley Orgánica 8/2013, de 9 de diciembre, para la mejora de la calidad educativa. 30 de diciembre de 2013, num 295, pp 3 a 64.

Luque, A. y Carrión, J.J. (2013). Análisis del grado de satisfacción profesional del maestro de audición y lenguaje itinerante. European Journal of Education and Psychology, 6, (1), 55-68. ISSN 1888-8992

Navarro, M.J. (2008). La dirección escolar ante el reto de la diversidad. Revista de Educación, 347, 319-341. Recuperado de: https://idus.us.es/xmlui/handle/114 $\underline{41 / 67566}$

Orden de 25 de julio de 2008, por la que se regula la atención a la diversidad del alumnado que cursa la educación básica en los centros docentes públicos de Andalucía. 22 de agosto de 2008, num 167, pp. 7 a 14.

Orden de 20 de agosto de 2010, por la que se regula la organización y el funcionamiento de las escuelas infantiles de segundo ciclo, de los colegios de educación primaria, de los colegios de educación infantil y primaria y de los centros públicos específicos de educación especial, así como el horario de los centros, del alumnado y del profesorado. 30 de agosto de 2010, num 169, pp 9 a 14.

Real Decreto 1344/1991, de 6 de septiembre, por el que se establece el currículo de la Educación Primaria (1991). España. 13 de septiembre de 1991, num 220, pp 30226 a 30228.

Real Decreto 696/1995, de 28 de abril, de ordenación de la educación de los alumnos con necesidades educativas especiales. 3 de junio de 1995, num 131, pp 3 a 13.

Real Decreto 82/1996 de 26 de enero, por el que se aprueba el Reglamento Orgánico de las Escuelas de Educación Infantil y de los Colegios de Educación Primaria (1996). España. 20 de febrero de 1996, num 44, pp 6061 a 6074.

Salas, M. R (2016). Reflexiones en torno a los maestros de pedagogía terapéutica. Padres y maestros. 365, 6-11. doi: pym.i365.y2016.001 